\title{
Influence of travel vlog: Inputs for destination marketing model
}

Abad, Princess Elisha S.

Lyceum of the Philippines University Batangas, Philippines (prncssabad08@gmail.com)

Borbon, Noelah Mae D. $\$

Lyceum of the Philippines University Batangas, Philippines (nmdborbon@lpubatangas.edu.ph)

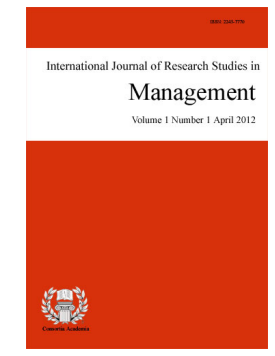

ISSN: $2243-7770$ Online ISSN: 2243-7789

OPEN ACCESS

\section{Abstract}

Travel vlogs are thought to have shaped destination credibility and effectively strengthened a perceived destination image. Opinions, reviews, and a live journey create a lifelike experience that encourages the desire to visit a location. The purpose of this research is to look into the possibilities of travel vlog inputs for destination marketing. The research was carried out among the residents of Sta. Cruz, Laguna in a descriptive-correlational method; the descriptive design provided an overview of actual cognition, feelings, and actions within the group while the correlational approach was used to assess the relationship between the factors affecting travel decision-making process and tourists' destination choice. A researcher-made questionnaire was utilized to determine the degree of influence for each variable. Results indicated that with regards to travel-related decisions, people tend to be impacted by travel vloggers more especially in terms of the perceived credible information. Further, the findings revealed that vloggers had a significant impact on people's decision to travel in terms of cognitive, emotional, and epistemic values. Furthermore, there is a strong link that suggests that the better the travel-related decisions, the better the destination choice. Finally, the research developed a destination model that recommends an effective strategy for Laguna Tourism in preserving and improving destination attributes.

Keywords: credibility, destination choice, influencers, travel decision-making process 


\section{Influence of travel vlog: Inputs for destination marketing model}

\section{Introduction}

The use of Internet has been predominant in the Travel Industry and the travel influencers has become an efficient way for many Hospitality and Tourism businesses to engage with their target market and to create brand recognition. Today, the industry cannot be reliable without the opinion of travel vlogs-which plays a major role in the promotion of destinations. A vlog is a film recording about an individual's life and as the term signifies, it is a video journal which records one's thoughts, opinions, and experiences for internet publication (Baker, 2019). According to Ontiveros (2016), travel vlogs have become increasingly relevant for destinations as written content offers travelers the ability to share travel insights that inspire others to consider visiting the destination.

As a field of academic research and an area of interest to the tourism industry, destination management and marketing remains a key issue. However, in recent years, DMOs (destination management organizations) have seen less government funding and have become more reliant on commercial revenue to fund their core activities (Li et al., 2017). While travel vloggers shake the travel industry, they also shape the way tourists make decisions about travel. Although it's challenging and thrilling to travel, these channels offer a traveler a closer insight at the understanding of his travel choices. Travel preferences are known to be unpredictable - they shift periodically and so require the industry to adopt these evolving expectations.

Online video content has been very strong in the travel and hospitality market in recent years. People enjoy watching YouTube videos before going on a trip to gather general feedback, ratings, but above all, they enjoy listening and watching to real-life stories and interacting with creators. A data from Think with Google year 2017 shows a percentage of $48 \%$ that indicates the population of YouTube subscribers in different travel vlogs while travel brands itself has only $19 \%$ of the overall statistics - showing that travelers are more apt these days to rely on actual videos and truthful travel vlog reviews. Ontiveros (2016) also claimed that it offers a rare opportunity to explain how travelers live the trip the destinations hold with them. He added as well that it provides illusion of the destination brand, which can be represented in numerous travel blogs and the perception of its contents as a modern technical innovation is important for tourism marketers.

According to Seyidov and Adomaitiene (2016), it is accepted that destination is an interactive environment for customers and not just a tourism commodity, it is a term which is subjectively understood and depends on a wide variety of factors by consumers. The decisions of travelling of tourists are not based on one single choice (such as destination, accommodation, or travel companions), but rather it is a complicated decision with many alternatives around (Shaikh et al., 2020). Arpornpisal (2018) said that the aim of any marketer is to know how consumers decide and how to help them decide to purchase the goods or services. Marketers, however, include heterogeneous client categories that, in turn, adhere differently, during the process of purchasing decisions and the actual procurement of the entire tourist package: tourist destinations, attractions, tourist features, transport mode to from the destinations and attractions (Fred, 2015). However, the growing digital era increases the travel decision-making process and stimulates considerable interest in visiting destinations. Based on the study conducted by Cunanan (2015), he claimed that globalization happens, making it possible that enthusiastic travelers share online travel information, and contribute to increasing the desire for traveling thus, the exchange of travel experiences encourages local and foreign tourism. Moreover, in terms of purpose and information to use, online outlets like travel vlogs are favored to readers in contrast with offline sources (Cunanan 2015).

The purpose of the study, therefore, is to analyze how the underlying factors relating to travelers' decision-making process and their choice of destination are moved by the inputs of travel vloggers. Further, the study will focus on how perceived relevance of travel vlogs' contents affects the behavioral intention of a traveler to purchase a tourism product. Thoroughly, it will assess the extent of influencers in creating brand 
awareness for many Hospitality and Tourism businesses. The study is well-timed and sensible to discuss as the industry is trying to bounce back amidst COVID-19. The country has been hit by the pandemic and the industry is one of the most affected industries. Tourism industry generated 12.7\% of the country's GDP year 2019 and substantially providing a huge number of 5.71 million jobs nationwide in the same year. According to statistics released by the Department of Tourism, foreign tourism sales dropped to 8.5 billion in the first quarter, a decrease of $36 \%$ from revenues over the same time last year. And as the industry faces the "New Normal", it urges to restore the tourists' confidence, tranquility, and well-being to travel. The ability of businesses participating in the travel industry with travel influencers could be a productive way to build an online image of a place and to encourage safer tourism. Moreover, it can represent positive experiences that can be utilize in destination marketing.

The figure demonstrates that each variable relates to one another to the potential effect of the input of travel vloggers. It indicates that the factors under each dependent variable will be affecting each other depending to the extent of how much travelers are affected by these travel vloggers.

Factors affecting Travel-Decision

Making Process

\section{Factors affecting Tourists'}

Destination Choice

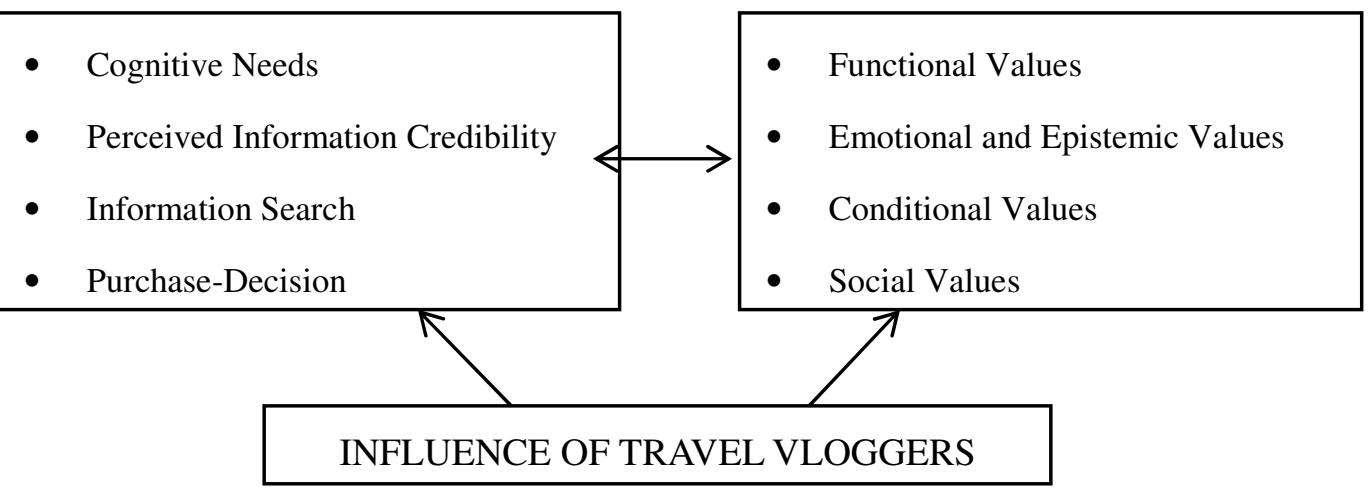

Figure 1. Conceptual Framework

\subsection{Objective of the Study}

The purpose of the study is to examine how vlogs influence travelers' decision-making process and their preferences for a travel destination. Specifically, it sought to; (1) describe the demographic profile of the respondents in terms of age, and sex as well as their psychographic profile in terms of frequency of travel, travel companion, and methods of collecting travel information, and reason for travel most of the time; (2) determine the level of how respondents are influenced by travel vloggers in decision-making process in terms of cognitive needs, perceived information credibility, information-search and purchase decision; (3) determine the degree of how respondents are influenced by travel vloggers in choosing a destination to visit in terms of functional values, emotional and epistemic values, conditional values, and social values; (4) identify the significant difference of the respondents' responses to travel vloggers' influence in decision-making process and destination choice when grouped according to their demographic and psychographic profiles and; (5) test the significant relationship between the influence of travel vloggers' in decision-making process and destination choice. Finally, the study seeks to develop destination marketing model with the influence of travel vloggers.

\section{Methodology}

\subsection{Research Design}

The study used descriptive and correlational research designs to collect and analyze the needed information. 
The descriptive design was providing an outline of actual thought, emotions, and actions within a certain category of individuals. While correlational method was measuring the relevance between two or more variables and asses the relationship among them. Both are important parts of the study as it helped the researcher make optimistic and calculated results. The purpose of using these designs is to create an analysis of the present market scenario and allowing comparison of two or more variables. It involves observation of behavior to describe factors objectively and thoroughly. Moreover, it described and forecast the natural relation between variables in the physical world without the researcher having to modify or adjust them.

\subsection{Respondent of the Study}

The respondents of the study were the locals of Sta. Cruz, Laguna with no characteristics such as gender, and age but with travel history or travelling is a hobby and likely to follow travel influencers. A total of 385 qualified respondents were be expected to support a good result of the study. The number was determined by using a $\mathrm{G}^{*}$ Power version 3.1.9, with the effect size of 0.25 , a power probability of 0.05 and an alpha level of 0.05 using priori test. The participants were consecutively selected according to the researcher's convenient accessibility. The sampling process were at end when the desired numbers of participants are reached.

\subsection{Instrument of the Study}

In this study, a researcher-made questionnaire used, utilizing the recent review of literature. The questionnaire was classified into two (2) sub-categories. The first set concerns the degree of impact of vloggers in the travel decision-making process of the respondents in terms of- cognitive needs, perceived credibility of information, information search and purchasing decisions. The second set is the degree to which tourism vloggers affect the choice of a tourist destination in terms of - functional values, emotional and epistemic values, conditional values, and social values. To measure the degree of responses for each factor, a 4-point Likert scale will be used with variations from "always" to "never". A statistician together with three (3) field experts were evaluate the questionnaire. The researcher would then perform a pilot test with thirty (30) people, who were not included in the survey proper, to measure the reliability of the questionnaire. The Cronbach Alpha Result for Travel-Related Decision is 0.821 while for destination choice is 0.766 . Based on rules of thumbs, the questionnaire is good and acceptable.

\subsection{Data Gathering Procedure and Analysis}

The researcher conduced a convenient sampling to facilitate the survey. Prior the survey proper, since the researcher used a self-made questionnaire, a pilot testing to at least thirty (30) respondents was conducted. The survey was distributed through Google forms. Several methods shall be used by the researchers to reduce the probability of common methodological bias. On the survey proper, respondents were first informed that their participation were voluntary. Second, they were informed that they should treat the questionnaire like a reflection and not to test any ability. Third, they will be assured to receive strict confidentiality and so their names were never being asked as so as their e-mail addresses for the online form. Fourthly, all returned forms are kept in an online archive with protected passwords.

To perform data analysis, the following statistical tools were used. Frequency and percentage distribution were used to describe the demographic profile of the respondents. Weighted means and ranking were used to determine the level of how respondents are influenced by travel vloggers in decision-making process in terms of cognitive needs, perceived information credibility, information-search and purchase decision and degree of how respondents are influenced by travel vloggers in choosing a destination to visit in terms of functional values, emotional and epistemic values, conditional values, and social values. The result of Shapiro-Wilk Test revealed that p-values of four major variables are less than 0.05 which means that the data set is not normally distributed. Therefore, Mann-Whitney U test for two groups and Kruskal Wallis test for three groups were used as part of the non-parametric tests to determine the significant differences. Likewise, Spearman rho was used to test the 
Influence of travel vlog: Inputs for destination marketing model

significant relationship between the two variables. In addition, all data were treated using a statistical software known as PASW version 26 to further interpret the result of the study using an alpha level of 0.05 .

\section{Results and Discussion}

Table 1

Demographic profile of the respondents

\begin{tabular}{|c|c|c|}
\hline Age & Frequency & Percentage $(\%)$ \\
\hline 22 and below (GenZ) & 143 & 37.10 \\
\hline 23 - 38 y/o (GenY) & 73 & 19.00 \\
\hline $39-54$ y/o $($ Gen $X)$ & 123 & 31.90 \\
\hline 55 and above (Baby Boomers) & 46 & 11.90 \\
\hline \multicolumn{3}{|l|}{ Sex } \\
\hline Male & 159 & 41.30 \\
\hline Female & 226 & 58.70 \\
\hline \multicolumn{3}{|c|}{ Frequency of Travel before Pandemic } \\
\hline Once a month & 187 & 48.60 \\
\hline 2 times a month & 130 & 33.80 \\
\hline 3 times or More than in a month & 68 & 17.70 \\
\hline \multicolumn{3}{|l|}{ Travel Companion } \\
\hline Solo Traveler & 54 & 14.00 \\
\hline With family or relatives & 182 & 47.30 \\
\hline With friends & 106 & 27.50 \\
\hline Organized groups & 43 & 11.20 \\
\hline \multicolumn{3}{|c|}{ Methods of collecting travel information } \\
\hline Friends and Families & 175 & 45.50 \\
\hline Blogs and Vlogs & 140 & 36.40 \\
\hline Magazines/Newspapers & 50 & 13.00 \\
\hline Other platforms & 20 & 5.20 \\
\hline \multicolumn{3}{|c|}{ Reason for travel most of the time } \\
\hline Relaxation & 135 & 35.10 \\
\hline Family orientation & 116 & 30.10 \\
\hline Business Travel & 49 & 12.70 \\
\hline Leisure & 85 & 22.10 \\
\hline
\end{tabular}

Table 1 presents the characteristics of the respondents. In terms of Age, majority of the respondents are ages 22 and below with 143 or 37.10 percent followed by the age bracket of 39 to 54 with 31.90 percent. This is followed by ages 23-38 with 73 or 19 percent and lastly, those of 55 years old and above with 46 or 11.90 percent. Most of the respondents are ages 22 years old since they are those who are into watching travel vlogs, they may not have the luxury of traveling and yet they tend to watch vlogs, Majority of the respondents are female with 226 or 58.70 while others are male with 159 or 41.30 percent. Female loves to travel it is natural for them to go out and seek for fresh new adventure and just hang out with friends as compared to men, they tend to use their free time to just stay at home watch movie or just rest. With regards to the frequency of travel before pandemic, most of the respondents are traveling for once a month with 187 or 48.60 percent. While 33.80 percent or 130 of the respondents are traveling for 2 times a month and the rest or 17.70 percent are traveling for 3 times a month or more. Traveling for at least one a month is already an achievement for most people. Due to the busy schedule and time and money constraint that limits them to travel more often.

As to the travel companion, 182 of the respondents or 47.30 percent are traveling with family or relatives while 27.50 percent are traveling with friends. 54 of the respondents or 14 percent are solo traveler and the rest are traveling with organized groups or with 11.20 percent. Filipino are known for being family oriented. They usually have family day or time just hangout on a weekend and celebrate occasion through traveling or going to different places. Most of the respondents are collecting travel information from their friends and families with 175 or 45.50 percent followed by blogs and vlogs with 140 or 36.40 percent while others are collecting 
information other platform with 5.20 percent and through magazines and newspaper with 50 or 13 percent. Still, even though there are online advertisement, newspaper or other platform for information, people would still go after the recommendation and validation from their friends or families. Since this is for them, the most credible source since the information being relayed are based on their experiences and observation.

\section{Table 2.1}

Travel-related decisions in terms of cognitive needs

\begin{tabular}{|c|c|c|c|}
\hline & WM & VI & $\mathrm{R}$ \\
\hline $\begin{array}{l}\text { 1. I usually learn about domestic and international destination through travel vlogs and } \\
\text { have the impulse to travel. }\end{array}$ & 3.40 & Often & 1 \\
\hline 2. Travel vlogs' contents address my needs. & 3.31 & Often & 2.5 \\
\hline 3. I usually follow travel guidelines shown in travel vlogs. & 3.31 & Often & 2.5 \\
\hline Composite Mean & 3.34 & Often & \\
\hline
\end{tabular}

Table displays the travel-related decision in terms of cognitive needs. The composite means of 3.34 indicates that the respondents often experience this need. Among the indicators that stated: I usually learn about domestic and international destination through travel vlogs and have the impulse to travel (3.40) ranked first and followed by statement as Travel vlogs' contents address my needs and I usually follow travel guidelines shown in travel vlogs tied in the same weighted mean of 3.31 .

Learning about domestic and international destination through travel vlogs and have the impulse to travel got the highest mean score of 3.40. Learning concepts about the domestic and international destination are commonly features various travel vlogs. Through this, more than marketing and a tool for pushing people to book it is a source of information for the audience to learn something. Vlogs conveys additional information about the product or service from the perspective of the audience, and it is one of the most important aspects of attraction that encourages audiences to participate in an experience. This is supported by Hsu (2020) concluded that social media has exceeded conventional types of media in terms of prominence, and if marketing teams can use it to build marketing and a feeling of connection among customers, it can be an efficient tool for creating flow and thereby raising the probability of impulse purchases. Tourists have a variety of requirements, and a venue that can accommodate these requirements is ideal. Tourists, likewise, would depend on the criteria they set for choosing their destinations. People have a variety of options ranging from activities to facilities, making travel both exciting and challenging. One of the most researched aspects of tourism is the decision-making process (Fred, 2015). In a study of Zhumadilova (2016), Vlogs influence the audience's philosophy known as reflection - an impact on audiences through the internet in which audiences experience the details in the real world through the incorporation of video content. As travel audiences gain authentic and reliable information about the destination and facilities, the degree of cognitive engagement increases.

While items such as travel vlogs' contents address the needs and usually follow travel guidelines shown in travel vlogs obtained the same mean value of 3.31 verbally interpreted as often. More often, the content of the travel vlogs doesn't contain the needs of the audience, however there are instances these contents are helpful in such a way that its significance to the current situation and is relevant to the current trends. Also, there are times that travel guidelines are not featured in the content of the travel vlogs since most of the contents featured the lived experience during the trip. The social media is by far the most suitable way of comprehensive reviews, recommendations, and site information for ensuring a single destination's reputation. Nhon and Thu, (2014) Information sharing has been much easier, and there are now more information sources available for future visitors. It has been discovered that the greater the number of internet users, the more they can judge the reliability of online content. Whereas Arora and Lata (2020) found out that using the YouTube channel, adoption, comprehensiveness, significance, timeliness, source knowledge, and attitude were found to be the most important predictor of a traveler's destination intention to visit. Furthermore, the statistical significance of source trustworthiness and accuracy was not discovered.

52 Consortia Academia Publishing (A Partner of Tourism Educators and Movers of the Philippines) 
Influence of travel vlog: Inputs for destination marketing model

Table 2.2

Travel-related decisions in terms of perceived information credibility

\begin{tabular}{|c|c|c|c|}
\hline & WM & VI & $\mathrm{R}$ \\
\hline $\begin{array}{l}\text { 1. I believe that the travel information in travel vlogs is credible enough to help the tourist to } \\
\text { be informed. }\end{array}$ & 3.40 & Often & 2 \\
\hline $\begin{array}{l}\text { 2. The attitude of the travel vloggers has a great impact on my own preference, intention and } \\
\text { information processing. }\end{array}$ & 3.42 & Often & 1 \\
\hline 3. The contents of travel vlogs will become an attraction I will definitely go. & 3.36 & Often & 3 \\
\hline Composite Mean & 3.39 & Often & \\
\hline
\end{tabular}

Legend: 3.50 - 4.00 = Always; 2.50 - 3.49 = Often; 1.50 - 2.49 = Sometimes; $1.00-1.49$ = Never

Table displays the travel-related decision in terms of perceived information credibility. The composite means of 3.39 indicates that the respondents often experience this need. Among the indicators that stated: the attitude of the travel vloggers has a great impact on my own preference, intention, and information processing (3.42) ranked first and followed by statement as I believe that the travel information in travel vlogs is credible enough to help the tourist to be informed (3.40) and the least statement is that contents of travel vlogs will become an attraction I will definitely go (3.36).

The item, attitude of the travel vloggers has a great impact on my own preference, intention, and information processing, got the highest mean score of 3.40 verbally interpreted as often. Travel vloggers are considered as influencers. Influencers in such a way that their words, actions, and behaviors influenced the audience to do action after watching their vlog. This may affect the decision of the viewers whether they will believe it or not, whichever the information that have been cascaded through that vlog will remain in the memory bank of the viewer and somehow will affect or influence the audience in later use. Virtual travel information has a positive impact on the viewer's understanding and feelings about their desired destination and services. The reliability of third-party data is critical for people to use it in their decision-making. According to Gretzel (2018), Influencers also enable tourism promoters to communicate with consumers directly. In addition, when influencers are compensated for their endorsements/contents, one difficulty that many travel marketers and influencers face is how to convey credibility. While for Tanford and Montgomery (2015) the use of traveler feedback and ratings, online content generation visibility may have a direct impact on consumers' expectations and purchases of travel goods. According to the studies, there is an improved subjective standard with favorable observation and a decline in visits to tourist destinations and purchasing intentions.

While item such as the contents of travel vlogs will become an attraction, I will definitely go obtained the lowest mean value of 3.36 followed by travel information in travel vlogs is credible enough to help the tourist to be informed having the mean value of 3.40 verbally interpreted as often. Since it is evident in the previous discussion on the profiling of the respondents that it is their family and friends whom they are getting information with and so this would have a question on whether the sources being delivered through travel vlog is credible. Since not everything on the internet is reliable it is important for travel bloggers to maintain connection with their audience so that the success of the travel blogs that they will create well maintained a credible and reliable source for the tourists. Consumers in the tourism industry should look into ways to create memorable experiences, especially once-in-a-lifetime travel.

Tourists are more interested in the experience of themselves than in the experience of the venue, and they invest a great deal of time, energy, inspiration, and engagement in these market activities, which have long been expressed and developed into a permanent, personal sense of identity Because of consumers' skepticism about how they are treated, social media sites are evolving to be successful marketing platforms. However, there is a need to be careful about how best to create relationships through value development. Thus, to have connections and an awareness that relationships must be built through involvement, trust, and loyalty, as well as interaction and communication (Zhang \& Chikwaya, 2018). According to Luo and Zhong (2015), The impact of transmitted information was greater than the impact of the decision-making process. As exciting new technologies continue 
to reshape online marketing and people's decision-making processes. Thus, in the data presented by Think with Google last 2014 - YouTube reveal that travelers are watching more video online than ever before, with travel-related content views up 118 percent year over year, and evidence suggests that travelers are using mobile devices to always consume content and in all places.

Table 2.3

Travel-related decisions in terms of information-search

\begin{tabular}{llll}
\hline & WM & VI & R \\
\hline $\begin{array}{l}\text { 1. I prefer watching travel vlogs to received useful travel information. } \\
\text { 2. Before travelling, I watch two or more vlogs to have an idea to the travel destination. }\end{array}$ & 3.35 & Often & 2 \\
3. Information about food, accommodation, shopping, and entertainment in travel vlogs has a & Often & 3 \\
strong influence for me & 3.41 & Often & 1 \\
& 3.36 & Often \\
\hline Cegend: $3.50-4.00=$ Always; $2.50-3.49=$ Often; $1.50-2.49=$ Sometimes; $1.00-1.49=$ Never & &
\end{tabular}

Table displays the travel-related decision in terms of information search. The composite mean of 3.36 indicates that the respondents often experience this needs. Among the indicators, Information about food, accommodation, shopping, and entertainment in travel vlogs has a strong influence for me (3.41) ranked first and followed by statement as I prefer watching travel vlogs to received useful travel information (3.35) and the least statement is Before travelling, I watch two or more vlogs to have an idea to the travel destination (3.31).

The item, Information about food, accommodation, shopping, and entertainment in travel vlogs has a strong influence for the tourist, got the highest mean score of 3.41 verbally interpreted as often. Since the travel blog contains the experience of the vlogger in terms of the hotel that they checked in, the food that they eat and even the activities that they do in the destination; surely this will have a great effect or influence on the viewers since it is more on the experience that they are showing in the travelblog this is very important in essential to provide in the travel bug since all the information is based not merely on a paper or brochure but this is truly based on their experience. The videos, as well as the comments from viewers, support the assertion that travel vloggers and their vlogs play a key role in creating an online destination image and eventually have an impact to the decision of the tourist. The possibility of purchasing a certain 'promise' in deciding a tourist destination is linked to the choice to support a tourist destination (Werenowska \& Rzepka, 2020). Even though there is an increasing knowledge of sustainable travel, 'widely known' YouTube influencers were slow to respond and include sustainability elements in their communications, significant purpose is higher than expected. It is vital to increase the number of 'popular' social media influencers that support sustainable travel (Chu, 2020). Both the stimulus ingredients and the perceiver's characteristics have an impact on an image. The importance of the location description in the consumer's destination selection is apparent when these ideas are combined. In the field of tourism, decision-making centered on destination selection, which is equivalent to holiday destination selection (Branch, 2020).

While item such as watching two or more vlogs to have an idea to the travel destination got the lowest mean score of 3.31 followed by watching travel vlogs to received useful travel information having the mean value of 3.35 verbally interpreted as often. For one to travel it is not a requirement for them to watch travelblog however this may help them in acquiring knowledge or information about that the destination. Blogs are useful in such a way that this is a source of personal experiences of the travel bloggers this would enable that the few words or audience to have an idea of what they could be expecting into the destination they will go to. Truly, knowledge towards a destination much as to the reliability and quality have influenced the creation of the destination image. Zhumadilova (2016) discussed that the picture of the destination consists of many information sources. Even though visitors never arrived at the destination, a mental image of it could be created in their minds. In this case, the destination's image is based on prior knowledge of historical patterns, the country's political and economic situation, as well as details on social life and previous image. Individual interests and country. In addition, Liang, (2020) considers travel vlog mostly as repository of tourism knowledge and investigates its representation of

54 Consortia Academia Publishing (A Partner of Tourism Educators and Movers of the Philippines) 
destination photos, thus contributing towards tourism literature and having potential significance for destination management organizations. Interest is defined as a desire to buy something; it can also be defined as consumer behavior in which they are interested in buying something. Meanwhile, tourism is closely linked with the media because it has a direct impact on the credibility of potential tourist destinations, influencing future tourist destination choices. (Garg, 2015).

Table 2.4

Travel-related decisions in terms of purchase decisions

\begin{tabular}{|c|c|c|c|}
\hline & WM & VI & $\mathrm{R}$ \\
\hline $\begin{array}{l}\text { 1. Travel vlogs recommend food, accommodation, shopping, and entertainment that excite } \\
\text { travelers to go for it. }\end{array}$ & 3.40 & Often & 1 \\
\hline $\begin{array}{l}\text { 2. The travel information in travel vlogs has a great impact deciding on my travel mode } \\
\text { (self-travel, group travel, self-driving travel). }\end{array}$ & 3.39 & Often & 2 \\
\hline 3. Travel vlogs influence how long I travel and stay in a specific destination. & 3.30 & Often & 3 \\
\hline Composite Mean & 3.36 & Often & \\
\hline
\end{tabular}

Table 2.4 displays the travel-related decision in terms of purchase decisions. The composite mean of 3.36 indicates that the respondents often experience this needs. Among the indicators, indicator that travel vlogs recommend food, accommodation, shopping, and entertainment that excite travelers to go for it. (3.40) ranked first and followed by statement as the travel information in travel vlogs has a great impact deciding on my travel mode as to self-travel, group travel, self-driving travel (3.39) and the least statement is that travel vlogs influence how long I travel and stay in a specific destination (3.30).

The item, Travel vlogs recommend food, accommodation, shopping, and entertainment that excite travelers to go for it, got the highest mean score of 3.40 verbally interpreted as often. Recommendation from the travel vloggers of the food hotel or accommodation, shopping center and activities to do in that destination is an essential content for travel blogs this would entice the viewers to also experience or do what the travel bloggers shared as in the content of their vlogs. Tourism should put in more effort to predict the needs of this consumer segment and find out how to best support younger and older seniors. Both the stimulus ingredients and the perceiver's characteristics have an impact on an image.

The importance of the location description in the consumer's destination selection is apparent when these ideas are combined. In the field of tourism, decision-making centered on destination selection, which is equivalent to holiday destination selection. The market is appealing due to the wealthy senior market and longer life expectancy. However, Pestana et al. (2020) believe that due to the accessibility and impact of social media, any unpleasant encounters can be notified appropriate among potential senior tourists, jeopardizing the commercial potential, and emphasizing the importance of understanding the nuances of the senior tourist market. A study of Pamuji et al. (2020) illustrated that in comparison to text-based and picture-based sites, a travel vlog has the advantage of serving as a guide for potential tourists before they decide to visit a destination. Travel vlogs are influencing travelers' destination choices; they've discovered that these videos have a proclivity to go viral and are then accepted as a perceived representation of online destinations in the online world and to be used to show them to the public through social media.

While item such as Travel vlogs influence how long their travel and stay in a specific destination got the lowest mean score of 3.30 followed by travel information in travel vlogs has a great impact deciding on their travel mode (self-travel, group travel, self-driving travel having the mean value of 3.36 verbally interpreted as often. Travel logs is an essential marketing tool however this doesn't influence on the duration or how long the traveler would stay in a destination this is basically because the duration of their trip may vary for several reason one is the cost the money that they would spend into the desk the trip another reason is the time availability. There people do not have the luxury in the money to spend as compared to other travel bloggers this may vary 
depending on their status in life also the time availability with also may be different since not everyone is a freelancer or have the free time to travel for a very long time. Hu et al., (2016) affirmed that the sense of belonging of customers are greatly affected by a vlogger's perceived attributes and attitude interpersonal attraction.

In other terms, considering that a character's perception affects the vlogger's consistency and functionality, a vlogger's physical appearance and attitude perceived social are essential factors. of origin influence the design of goals and the method of choice. Relatively from Jeyaraja and Arunachalam (2020), The decision-making process is based on the knowledge representation of travelers' thoughts, and it is highly influenced by what they see. Travel details in video format also have a greater impact on travel markets. According to Majeed et al. (2020), Before making a travel plan, visitors look for information on the best destination and hotel on the internet. The use of ICT devices (laptops, iPads, and smartphones) by visitors has boosted the use of the Internet in tourism planning, promotion, and usage around the world. As a result, detailed online travel information is now available in just a few clicks.

Table 3.1

Destination choice in terms of functional values

\begin{tabular}{llcc}
\multicolumn{1}{c}{ Travel vloggers feature destinations that are... } & WM & VI & R \\
\hline New and something that is not yet discovered & 3.32 & Often & 3 \\
Popular with exotic local delicacies and exotic food & 3.38 & Often & 2 \\
Destinations with quality infrastructures and unique tourist attractions & 3.44 & Often & 1 \\
\hline \multicolumn{1}{c}{ Composite Mean } & 3.38 & Often \\
\hline
\end{tabular}

Legend: $3.50-4.00=$ Always; $2.50-3.49=$ Often; $1.50-2.49=$ Sometimes; $1.00-1.49=$ Never

Table present the destination choice in terms of functional values. The composite means of 3.38 indicates that the respondents often experience this value. Among the indicators, destinations with quality infrastructures and unique tourist attractions. (3.44) ranked first and followed by statement as there are Popular with exotic local delicacies and exotic food (3.38) and the least statement is that there are New and something that is not yet discovered (3.32).

Destinations with quality infrastructures and unique tourist attractions (3.44) got the highest rank which have the verbal interpretation as often. People tend to travel mainly because of adventure seeking for different tourist instruction that would enable them to not only relax but experience life. Having a quality infrastructure in the destination is essential and vital factor for the deciding behavior for the tourists. As a motivation, tourists may tend to travel to seek enjoyment and to fulfill that emotional being satisfied through going to different tourist destination which provide variety of facilities in amenities through quality infrastructure and unique tourist attraction. In addition, satisfaction is a mediator of motivations and travel intentions, and age is a factor. Emotions influence factors such as maintenance and expansion, happiness, and behavioral purpose. Therefore, feelings serve as a motivator for loyalty (Pestana et al., 2020). Also, according to Zahid and Ahmed (2017), it is a reward that businesses give to their customers in exchange for their loyalty, but only if businesses regularly provide high-quality products can their customers remain loyal. Consequently, despite a wide range of options, only high-quality suppliers will survive and prosper.

Relatively, New and something that is not yet discovered (3.32) got the least rank which have the verbal interpretation as often followed by Popular with exotic local delicacies and exotic food (3.38). Travel vlogs is a powerful tool for promotion and marketing for tourism. Discovering what is not yet discovered and featuring exotic locale the delicacies is a good content for travel vlogs however there are certainty that there is no assurance that this would provide the tourists with all the information that they would need with this this may influence or impact on their deciding factor. The lack of certainty surrounding Generation Y's standards could be affected by their relation to the internet's new platforms and the dispute about when the internet becomes prominent. A website that offers tools for managing influencer relationships, has compiled a list of popular 
travel-related online marketing promotional activities (Gretzel, 2018). In addition, Agbi (2019) stated that social media can form the picture of a tourist destination and affect decision-making through opportunities and experiences. Travel videos are everywhere and became an instant tool in marketing a destination. Thus, in the present, the presence of individuals or people with a positive image boosts public trust and influences the level of engagement and final decision on tourism service visits or experiences (Zhumadilova, 2016).

Table 3.2

Destination choice in terms of emotional and epistemic values

\begin{tabular}{lccc}
\multicolumn{1}{c}{ Travel vloggers highlights... } & WM & VI & R \\
\hline 1. New adventures to try in the destination & 3.47 & Often & 2.5 \\
2. Places to visit in the destination & 3.51 & Always & 1 \\
3. Sceneries that make you want to escape the everyday routine & 3.47 & Often & 2.5 \\
\multicolumn{1}{c}{ Composite Mean } & 3.48 & Often \\
\hline Legend: $3.50-4.00=$ Always; $2.50-3.49=$ Often; $1.50-2.49=$ Sometimes; $1.00-1.49=$ Never & &
\end{tabular}

Table present the destination choice in terms of emotional and epistemic values. The composite mean of 3.41 indicates that the respondents often experience this values. Among the indicators, travel vloggers highlight places to visit the destination (3.51) ranked first and followed by statement as travel vloggers highlights new adventures to try in the destination and Sceneries that make you want to escape the everyday routine tied in the same weighted men of 3.47 .

Places to visit in the destination (3.51) got the highest rank which have the verbal interpretation as always. One of the reasons why people watch is travel blogs is to decide on where to go, on what or where to visit. Through the vlogs, content may feature different destinations of the local or international places. The destination image of one locality and its competitiveness would really vary on how it was being promoted through digital or may it be in word of mouth. Furthermore, good service can elicit a positive emotional response, resulting in a bond between visitors and the location. A tourist will mainly consider visiting a vacation destination with well-known eminence features that correspond to their value. Two certain themes contribute to the overall destination image, that is inspired with both affective and cognitive images. There are also six factors that influencing the destination image creation and recognition in travel vlogs: vlog performers, destination impressions, travel purposes, sources of information, culture and language, video format, and social networking features (Liang, 2020). Thus, according to Phau et al. (2015), The capacity of a destination to elicit emotions or affective states is referred to as its emotional sense. In a variety of business decision contexts, affective-based value plays a significant role. As a result, a visitor would prefer visiting a location that has a pleasant atmosphere and can promote calmness and independence.

Relatively, Sceneries that make them want to escape the everyday routine and new adventures to try in the destination (3.47) got the least rank which have the verbal interpretation as often. People tend to travel mainly for relaxation and escape on their everyday routine and try different or new adventure however based on the result this me rank list due to the safety protocols since we have this new normal and pandemic this is no longer the priority of the tourist thus making health and security the number one priority of the tourist. The importance of a destination's ability to arouse curiosity, offer excitement, or satisfy a need for knowledge is referred to as epistemic values. A tourist inspired by epistemic principles will prefer options that satisfy a new or fashionable desire; a tourist would want to visit a location with completely new activities to try. The main drivers of consumer choice are usually expected to be objective meaning that constitutes the practical value - this assumption is based on the advanced theory of economic utility, popularly interpreted as 'rational economic person,' and are primarily attributed with dependability, stability, and price. The development of an influencer marketing industry including increased levels of professionalization amongst influencers, new ways of intermediaries enabling exchange processes, and new technical technologies being developed to support the aspects of online advertising is an important trend in influencer marketing. As a result, keeping up to date on the new influencer marketing trends is important for the travel industry (Gretzel, 2018). 
Abad, P. E. S., \& Borbon, N. M. D.

Table 3.3

Destination choice in terms of conditional values

\begin{tabular}{lccc}
\multicolumn{1}{c}{ Travel vloggers shows... } & WM & VI & R \\
\hline 1. Good value for money and budget tips & 3.51 & Always & 1.5 \\
2. Safety guidelines in a specific destination & 3.51 & Always & 1.5 \\
3. Instructions on how to get there and other information of the destination & 3.49 & Often & 3 \\
\multicolumn{1}{c}{ Composite Mean } & 3.50 & Always \\
\hline Legend: $3.50-4.00=$ Always; $2.50-3.49=$ Often; $1.50-2.49=$ Sometimes; $1.00-1.49=$ Never & & &
\end{tabular}

Table present the destination choice in terms of conditional values. The composite mean of 3.41 indicates that the respondents often experience this values. Among the indicators, travel vloggers show good value for money and budget tips and Safety guidelines in a specific destination ranked first and tied in the same weighted men of 3.47 which was followed by statement as travel vloggers show instructions on how to get there and other information of the destination (3.49).

Safety guidelines in a specific destination and good value for money and budget tips (3.51) got the highest rank which have the verbal interpretation as often. In this time of pandemic safety guidelines is crucial and very important to everybody and not only with regards to safety and security more so with the financial security ensuring that they would get the value of what they paid for is as much as important to creating a quality travel experience that is safe and worth it. In addition, one of the factors that the tourist is considering and going to a place the safety and the price depends on ability of that destination. Whether they would provide at most safety guidelines or assuring the security of all the gas and providing quality service that is equivalent to what they paid for this would be one of the deciding factors for the tourists. Huang et al. (2017) confirms that understanding the relationship between destination choice as well as business clusters is crucial for developing sustainable cities, cultivating vibrant business clusters, and creating sustainable living. As people become more comfortable posting their locations and interactions on social media sites, such data can expose destination preferences, which can shed light on the complex relationships that is based on the factor for value of money and safety. Before purchasing travel-related goods, travelers must gather a vast amount of data to minimize the risk of purchasing tourism services, which stems from the experimental nature of most tourism product purchases. There are options for reaching and adapting before and after the journey (Matikiti-Manyevere \& Kruger, 2019).

Relatively, Instructions on how to get there and other information of the destination (3.47) got the least rank which have the verbal interpretation as often. Information about how to get there is no longer essential in indicating to the travel vlogs since there are different platforms such as Waze, Maps, other platform that would help them know where and how to get there is much more reliable too the tourists. However, this may rank least since this information on how to get there is not that the travel flag. Moreover the mode and means of transportation surely being presented in the vlogs. As a result, travelers are more likely to use digital services to make any tour-related decisions. Peralta (2019) claim that travel vloggers with their corresponding vlogs play an important role in developing an online experience concept of a location is backed by content and visualization of the images, as well as audience responses. Vlogs effectively create destination photos, which are necessary and fundamental for tourism destinations. Vlogs about travel are visual illustrations of travel experiences.

Table 3.4

Destination choice in terms of social values

\begin{tabular}{lccc}
\multicolumn{1}{c}{ Travel vloggers promotes... } & WM & VI & R \\
\hline 1. Culture and tradition of the destination & 3.40 & Often & 2 \\
2. Tourism business such as souvenir shops, restaurants etc. & 3.38 & Often & 3 \\
3. Good quality of life of the locals & 3.46 & Often & 1 \\
$\quad$ Composite Mean & 3.41 & Often \\
\hline
\end{tabular}

Legend: $3.50-4.00=$ Always; $2.50-3.49=$ Often; $1.50-2.49=$ Sometimes; $1.00-1.49=$ Never 
Table present the destination choice in terms of social values. The composite mean of 3.41 indicates that the respondents often experience this values. Among the indicators, travel vlog promotes good quality of life of the locals. (3.46) ranked first and followed by statement as travel vlog promotes culture and tradition of the destination (3.40) and the least statement is that travel vlog promotes tourism business such as souvenir shops, restaurants etc. (3.38).

Having good quality of life of the locals (3.46) got the highest rank which have the verbal interpretation as often. Presenting the culture and values and even the life of the residents is motivating the tourists to also experience what the vloggers and influencer presented through vlogs. The overall satisfaction of the tourists may also vary whether they also experience the good quality of life of the locals through interaction and engaging to their way of life. A tourist has many options for deepening his link with an antecedent. The extrinsic use of alternatives, rather than their intrinsic use, is the focus of conditional value. As a result, a visitor will choose a location that does not pose a threat to his security and safety. As supported by Caber and Albayrak (2016), that the overall satisfaction is measured by push and pull motives, which vary based on the level of experience of the visitors. In addition, there is a willingness to identify and accept one or more specific social classes, such as geographic, socioeconomic, and cultural ethnic groups, or to support these groups socially that is basically pertaining to their social values (Phau et al., 2015).

Relatively, Tourism business such as souvenir shops, restaurants (3.38) got the least rank which have the verbal interpretation as often followed by culture and tradition of destination (3.40). There are the reason businesses presented in the travel blogs such as souvenir shops restaurants in alike, however this is not at deciding factor for the audience whether they would go to that destination this is merely because that they have different opinion and personality. Also, there are tourists that have their own preference when it comes to souvenir shops or a shopping and more specifically on the type of restaurants that they would dine in. As a result, a tourist chooses to visit places that he or she has a connection to or aspires to visit. The preference for easily identifiable objects, as well as goods or services for sharing with others, is also influenced by social context. For example, a vacation destination may be chosen based on its social image rather than its functional values for the social image evoked. This is supported by the study of Fillimonau and Perez (2018) concluded on the importance of culture can also be seen in how visitors study destinations before traveling and how they view travel risks, affecting their desire to travel. Recommendations are provided about how to incorporate information about visitors' cultural contexts into tourism decision making and policy activities. Furthermore, a study conducted by Trinh and Nguyen (2019), Vloggers face a greater challenge than bloggers in terms of media selection and technical complexities, and a poorly executed vlog, which is not uncommon on the internet, can lead to confusion about the information and a satisfied impression, which can counteract the creative intent.

Table 4 presents the comparison of responses on travel-related decisions when grouped according to profile. It was observed that there was a significant difference on cognitive needs $(p=0.011)$ when grouped according to sex. This means that there was a significant difference exists and implies that the responses differ statistically. Based on the test conducted, it was found out that male have greater assessment on cognitive needs. When grouped according to frequency of travel before pandemic, there was a significant difference information-search since the obtained p-value of 0.046 was less than 0.05 alpha level. The results show that those who travel 3 times or more than in a month before pandemic have greater assessment on information-search. While those who travel with family or relatives have greater assesment on cognitive needs. Males have a different view as women. Men tend to focus more on the cognitive needs as to woman. Likewise, those who are traveling for three times and more in the mind is surely would have a greater assessment on information search basically because they have more experience and they have already been exposed to different tourism destination. Also, those who are traveling with their family or relatives also have a greater assessment on cognitive needs basically because those a companion are the most important people on their lives making sure that they would feel secured and be satisfied on the destination that they would be going into. 
Abad, P. E. S., \& Borbon, N. M. D.

\section{Table 4}

Difference of responses on travel-related decisions and destination choice when grouped according to profile

\begin{tabular}{|c|c|c|c|c|c|c|c|}
\hline Age & $\lambda^{2} \mathrm{c} / \mathrm{U}$ & p-value & I & Age & $\lambda^{2} \mathrm{c} / \mathrm{U}$ & p-value & I \\
\hline Cognitive Needs & 4.841 & 0.184 & NS & Functional Values & 3.761 & 0.288 & NS \\
\hline Perceived Information Credibility & 3.659 & 0.301 & NS & Emotional \& Epistemic & 11.743 & 0.008 & $\mathrm{~S}$ \\
\hline Information-Search & 4.205 & 0.240 & NS & Conditional Values & 9.896 & 0.019 & $\mathrm{~S}$ \\
\hline Purchase Decisions & 2.781 & 0.427 & NS & Social Values & 2.122 & 0.547 & NS \\
\hline \multicolumn{8}{|l|}{ Sex } \\
\hline Cognitive Needs & 15286.000 & 0.011 & $\mathrm{~S}$ & Functional Values & 1523 & 0.593 & NS \\
\hline Perceived Information Credibility & 17564.500 & 0.701 & NS & Emotional and Epistemic & 1504 & 0.498 & NS \\
\hline Information-Search & 17772.500 & 0.853 & NS & Conditional Values & 1364 & 0.150 & NS \\
\hline Purchase Decisions & 17354.500 & 0.560 & NS & Social Values & 1615 & 0.991 & NS \\
\hline \multicolumn{8}{|l|}{ Frequency of Travel before Pandemic } \\
\hline Cognitive Needs & 5.861 & 0.053 & NS & Functional Values & 5.337 & 0.069 & NS \\
\hline Perceived Information Credibility & 3.604 & 0.165 & NS & Emotional and Epistemic & 0.455 & 0.796 & NS \\
\hline Information-Search & 6.179 & 0.046 & $\mathrm{~S}$ & Conditional Values & 0.470 & 0.791 & NS \\
\hline Purchase Decisions & 2.619 & 0.270 & NS & Social Values & 0.742 & 0.690 & NS \\
\hline \multicolumn{8}{|l|}{ Travel Companion } \\
\hline Cognitive Needs & 11.194 & 0.011 & $\mathrm{~S}$ & Functional Values & 4.422 & 0.219 & NS \\
\hline Perceived Information Credibility & 7.030 & 0.071 & NS & Emotional and Epistemic & 2.287 & 0.515 & NS \\
\hline Information-Search & 5.695 & 0.127 & NS & Conditional Values & 1.788 & 0.618 & NS \\
\hline Purchase Decisions & 3.229 & 0.358 & NS & Social Values & 3.105 & 0.376 & NS \\
\hline \multicolumn{8}{|c|}{ Methods of collecting travel information } \\
\hline Cognitive Needs & 13.282 & 0.004 & $\mathrm{~S}$ & Functional Values & 7.055 & 0.070 & NS \\
\hline Perceived Information Credibility & 12.223 & 0.007 & $\mathrm{~S}$ & Emotional and Epistemic & 5.798 & 0.122 & NS \\
\hline Information-Search & 16.024 & 0.001 & S & Conditional Values & 1.508 & 0.680 & NS \\
\hline Purchase Decisions & 9.370 & 0.025 & $S$ & Social Values & 6.537 & 0.088 & NS \\
\hline \multicolumn{8}{|l|}{ Reason for travel most of the time } \\
\hline Cognitive Needs & 1.714 & 0.634 & NS & Functional Values & 0.538 & 0.910 & NS \\
\hline Perceived Information Credibility & 0.260 & 0.967 & NS & Emotional and Epistemic & 3.665 & 0.300 & NS \\
\hline Information-Search & 1.886 & 0.596 & NS & Conditional Values & 3.018 & 0.389 & NS \\
\hline Purchase Decisions & 0.340 & 0.952 & NS & Social Values & 0.973 & 0.808 & NS \\
\hline
\end{tabular}

Legend: Significant at $p$-value $<0.05$

This assessment on the following is very evident as people are different from each other they have different views and opinions making them unique as an individual. Correspondingly, when a product is licensed by a third party, it is purchased by those who view it through their applications or comments. Users form reference groups with which they compare or associate themselves. They have a major impact on purchasing patterns. The alleged advantage derived from a particular choice in relation to the decision-actual maker's position or circumstances. In the presence of antecedents that increase its functional or social significance, whether physical or social, an alternative gains conditional value. A contingency profile of their choice will be used to determine the base value. On a related study by Ponte el al. (2015) concluded that a general customer understanding of the completeness and authenticity of the information on the website surrounding both the resources provided and the processes used to complete an online transaction is referred to as data quality background. Then, based on the website's content quality, a customer can determine whether the website is appropriate for making an online purchase.

Lastly, there was also significant difference on travel-related decisions when grouped according to methods of collecting travel information. This means that the responses differ significantly and from the pairwise 
comparison, those who are reading magazines/Newspapers have greater assessment. Those people who tend to get information from in newspapers and magazine are seen as more meticulous in terms of having a favorable information about the tourist destination. Getting reputable source to expand their knowledge about the destination is crucial for them. Moreover, Vloggers who give favorable reviews to tourism are more likely to encourage their followers to travel with them. Tourism, on the other hand, are largely unaffected by negative feedback. Vloggers can expand their audience by personalizing their content and tips to certain audiences' tastes and supporting their reputation. Tourism could benefit from partnering with vloggers to improve sales (Wojciechowicz, 2020). A study conducted by Matikiti-Manyevere and Kruger (2019), Tourists usually seek for tourism destinations and tourist facilities on the social media and the internet sites instead of relying on information obtained from travel agents or tour companies.

Table also presents the comparison of responses on destination choice when grouped according to profile. It was observed that there was a significant difference on emotional and epistemic values $(p=0.008)$ and conditional values $(p=0.019)$ when grouped according to age. This means that there was a significant difference exists and implies that the responses differ statistically. Based on the pairwise comparison, it was found out that 22 and below (GenZ) has greater assessment on the Emotional and Epistemic Values and Conditional Values.

In today's generation most of the people ages 22 years old and below also known as the GenZ have significantly greater assessment on these values such as functional, emotional, and epistemic, conditional, and social values. At a very young age they already seen the value of certain choices that they are making in their lives. This is supported by of Dimitriou and AbouElgheit, (2019) Gen Zers, as younger customers, are far less loyal to brands than previous generations. They have a broader variety of choices to choose from. Since they have a much better working experience, they process more knowledge and requirements per alternative. As a result, technology allows Gen $\mathrm{Z}$ to become more effective in their decision-making.

Also, mostly in case of Gen Zers, the steps of the online decision-making phase are becoming more and more intertwined. Furthermore, the authors concur with previous research that defined the current decision-making paradigm as internet-based and more complex. As a result, a new central element joins the buyer decision-making phase of this new generation (Wei, 2016). In addition, according to McBride, (2016) Gen Zers are concerned about sustainable development and environmental issues, and they put a high emphasis on hotels that follow environmentally sustainable policies. Similarly, marketers in the travel and tourism industry may use this data to build innovative goods and services that Gen Zers might appreciate. For many tourism marketers, the value of emotional experience is an ongoing study. And with the industry evolving, personal travel experiences stimulate the idea of wanting to experience the same thing. Thus, the advent of travel vlogs influences the mind to travel. According to Trinh and Nguyen (2019), generation gap also claims that combining sensor elements in a video makes it easier to decipher the emotional and psychological importance of the advertising message addressing to the different need of different ages.

Table 5 shows the association between travel-related decisions and destination choice. It was observed that the computed rho-values indicates a moderate to a strong direct correlation and the resulted p-values were less than 0.01 alpha level. This means that there was a significant relationship exists and implies that the better the travel-related decisions, the better is the destination choice. Based on the result of the study it was seen that there is a correlation between the travel related decision and this decision choice. The decision of the tourists may vary the different factors.

The impact of the travel vlogs to the decision making of the tourists would also vary. Travel marketing have realized the tremendous value of message reinforcement and targeting that travel media influencers can bring. Tourism industry is an enticing target sector for influencers due to the prospect of travel rewards and the opportunity to align one's brand identity with attractive tourism brands (Gretzel, 2018). 
Abad, P. E. S., \& Borbon, N. M. D.

\section{Table 5}

Relationship between travel-related decisions and destination choice

\begin{tabular}{cccc}
\hline Cognitive Needs & rho-value & $p$-value & Interpretation \\
\hline Functional Values & $0.630^{* *}$ & 0.000 & Highly Significant \\
Emotional and Epistemic Values & $0.467^{* *}$ & 0.000 & Highly Significant \\
Conditional Values & $0.474^{* *}$ & 0.000 & Highly Significant \\
Social Values & $0.603^{* *}$ & 0.000 & Highly Significant \\
\hline Perceived Information Credibility & & & \\
\hline Functional Values & $0.680^{* *}$ & 0.000 & Highly Significant \\
Emotional and Epistemic Values & $0.574^{* *}$ & 0.000 & Highly Significant \\
Conditional Values & $0.598^{* *}$ & 0.000 & Highly Significant \\
Social Values & $0.684^{* *}$ & 0.000 & Highly Significant \\
\hline Information-Search & & & \\
\hline Functional Values & $0.650^{* *}$ & 0.000 & Highly Significant \\
Emotional and Epistemic Values & $0.614^{* *}$ & 0.000 & Highly Significant \\
Conditional Values & $0.561^{* *}$ & 0.000 & Highly Significant \\
Social Values & $0.685^{* *}$ & 0.000 & Highly Significant \\
\hline Purchase Decisions & & & Highly Significant \\
\hline Functional Values & $0.699^{* *}$ & 0.000 & Highly Significant \\
Emotional and Epistemic Values & $0.667^{* *}$ & 0.000 & Highly Significant \\
Conditional Values & $0.611^{* *}$ & 0.000 & Highly Significant \\
\hline Social Values & $0.716^{* *}$ & 0.000 &
\end{tabular}

Legend: Significant at p-value $<0.05$

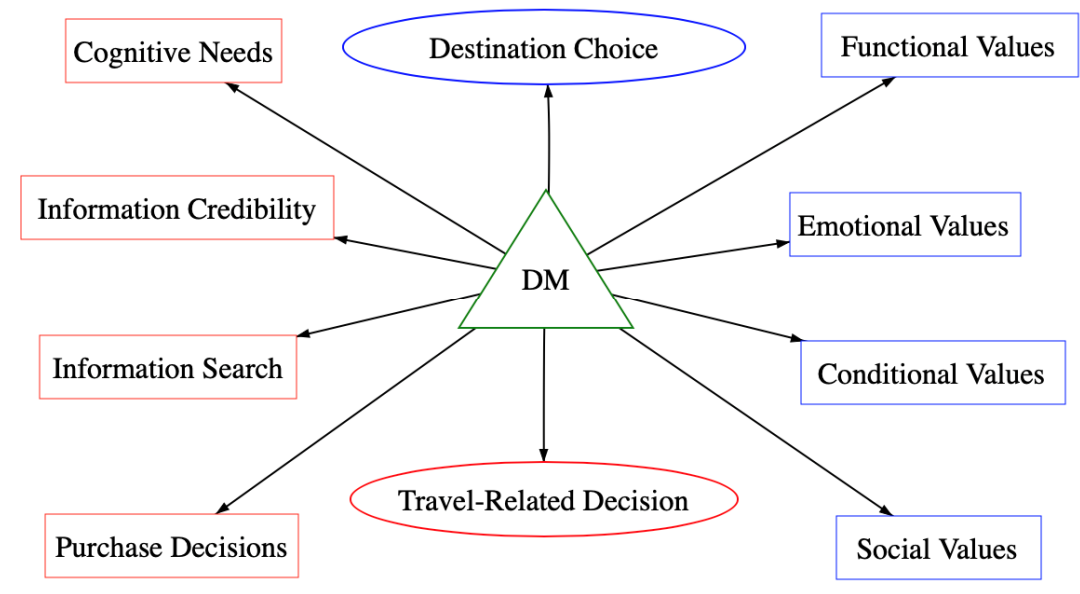

\section{Destination Marketing Model}

Figure 1. Destination Marketing Model

Figure 1 presents the model developed by the research. This reveals that for destination marketing it is essential to focus both on destination choice and travel related decisions. As the results are also consistent with the proposition that tourists attempt to ease the cognitive burden of selecting their destination by narrowing the decision-making calculus down to a smaller number of salient attributes. This suggests that an effective strategy for the Laguna tourism industry would be focus on maintaining and enhancing the quality of these eight destination attributes, rather than trying to spread its efforts and resources among them all. These characteristics 
are the most important in shaping destination choice; any of the others is likely to have only a minor impact on tourism arrivals and spending.

This is being supported by the study of Marasco et al. (2018) investigating the impact of virtual reality experiences on destination visit intentions, as allowed by the latest wearable devices. The findings of the study are important for destination marketing companies looking to create successful technology-based marketing strategies that address the pre-visit, on-site, and post-visit phases of the visitor journey. Thus, the role of destination management organizations (DMOs) in bringing stakeholders together is crucial. Stakeholder collaboration is beneficial to both stakeholders and destination (Abou-Shouk, 2018). In addition, Almeida and Garrod (2018) concluded that the most important factors influencing destination selection are generic and cross-cutting, suggesting that destination management and marketing should be more operationally focused than it is in many mature island destinations.

\section{Conclusion and Recommendation}

Most of the respondents of this study are in GenZ, ages 22 and below, Female. They are traveling once a month before the pandemic and traveling with their family and relative. Most of them are collecting travel information through their friends and families and traveling for relaxation. With regards to Travel-related decisions, people tend to be influenced by travel vloggers more specifically in terms of the perceived credible information. Respondents are influenced by travel vloggers in choosing a destination more specifically in terms of the conditional values as well as the emotional and epistemic values. It was found out that male have greater assessment on cognitive needs. The results show that those who travel 3 times or more than in a month before pandemic have greater assessment on information-search. While those who travel with family or relatives have greater assesment on cognitive needs and it was found out that 22 and below (GenZ) have greater assessment on the variables. This means that there was a significant relationship exists and implies that the better the travel-related decisions, the better is the destination choice.

Based on the findings, it was recommended for: Tourism Officers Laguna may tap different influencer or travel vloggers to promote the local tourist attraction in these videos maybe share two different social media platform to create awareness among the local and international market. There can be a Travel Vlog competition held to promote different tourism in several municipalities in Laguna. Department of Tourism may conduct seminars in workshop on promoting and marketing tourism in the new normal using social media platform like YouTube Facebook and Instagram. Travel Agencies or Tourism Businesses may be online help desk inserted at the end of the travel vlogs to cater queries and bookings for the future travelers. For the future researchers, they may conduct similar studies on the retention visit and guest satisfaction in Laguna tourism industry.

\section{References}

Abou-Shouk, M. A. (2018). Destination management organizations and destination marketing: adopting the business model of e-portals in engaging travel agents. Journal of Travel \& Tourism Marketing, 35(2), 178-188. https://doi.org/10.1080/10548408.2017.1350254

Agbi, A. (2019). Social media platforms and travel destination choices among international students in umea. http://umu.diva-portal.org/smash/record.jsf?pid=diva2\%3A1327650\&dswid=4784

Almeida, A., \& Garrod, B. (2018). A CATREG model of destination choice for a mature Island destination. Journal of destination marketing \& management, 8, 32-40. https://doi.org/10.1016/j.jdmm.2016.11.005

Arora, N., \& Lata, S. (2020). YouTube channels influence on destination visit intentions. Journal of Indian Business Research. https://doi.org/10.1108/JIBR-09-2019-0269

Arpornpisal, C. (2018, June 05). Tourism elements influence the decision making in traveling to visit Phra Pathom Chedi, Nakhon Pathom, Thailand. https://papers.ssrn.com/sol3/papers.cfm?abstract_id=3190064 
Abad, P. E. S., \& Borbon, N. M. D.

Battour, M., Ismail, M. N., Battor, M., \& Awais, M. (2017). Islamic tourism: an empirical examination of travel motivation and satisfaction in Malaysia. Current Issues in Tourism, 20(1), 50-67. https://doi.org/10.1080/13683500.2014.965665

Bhattacharyya, R. (2020, May 08). Influencer marketing: Can it make or break the travel and tourism industry?

Bosangit, C., Hibbert, S., \& McCabe, S. (2015). If I was going to die I should at least be having fun: Travel blogs, meaning and tourist experience. Annals of Tourism Research, 55, 1-14. https://doi.org/10.1016/j.annals.2015.08.001

Branch, J. (2020). The influence of traveler reviews on mobile applications on travel decision-making to Dubai. Journal of Theoretical and Applied Information Technology, 98(15).

Caber, M., \& Albayrak, T. (2016). Push or pull? Identifying rock climbing tourists' motivations. Tourism Management, 55, 74-84. https://doi.org/10.1016/j.tourman.2016.02.003

Chu, J. (2020). Sustainable travel on YouTube. Discussion and perception: How do YouTube travel vlogs discuss sustainable travel? How are they perceived?

Cunanan, E. (2017, May 05). Attitudes towards Travel Blogs and its Effect over

Dahiya, K., \& Batra, D. (2016, November). Tourist decision making: Exploring the destination choice criteria. Asian Journal of Management Research, 7(2), 140-153.

Dickson, A. (2019). Influencer Marketing Tourism Trends on The Rise for 2019.

Dimitriou, C. K., \& AbouElgheit, E. (2019). Understanding generation Z's travel social decision-making. Tourism and Hospitality Management, 25(2), 311-334. https://doi.org/10.20867/thm.25.2.4

Fan, Y., Chen, J., Shirkey, G (2016). Applications of structural equation modeling (SEM) in ecological studies: an updated review. Ecol Process, 5, 19 https://doi.org/10.1186/s13717-016-0063-3

Filimonau, V., \& Perez, L. (2018). National culture and tourist destination choice in the UK and Venezuela: an exploratory and preliminary study. Tourism Geographies. https://doi.org/10.1080/14616688.2018.1490342

Fred, B. (2015). The factors influencing the choice of tourist destinations and attraction sites among international tourists. http://scholar.mzumbe.ac.tz/

Garg, A. (2015). Travel risks vs tourist decision making: A tourist perspective. International Journal of Hospitality \& Tourism Systems, 8(1), 1-9. https://doi.org/10.21863/ijhts/2015.8.1.004

Gretzel, U. (2018). Influencer marketing in travel and tourism. Advances in social media for travel, tourism and hospitality: New perspectives, practice and cases, 147-156. https://doi.org/10.4324/9781315565736-13

How User Generated Content (UGC) Has Transformed Travel. (2019, April 04). https://www.simplevieweurope.com/

Hsu, C. L. (2020). How vloggers embrace their viewers: Focusing on the roles of para-social interactions and flow experience. Telematics and Informatics, 49, 101364. https://doi.org/10.1016/j.tele.2020.101364

Hu, X., Huang, Q., Zhong, X., Davison, R. M., \& Zhao, D., (2016). The influence of peer characteristics and technical features of a social shopping website on a consumer's purchase intention. Int. J. Inf. Manage, 36(6), 1218-1230. https://doi.org/10.1016/j.ijinfomgt.2016.08.005

Huang, A., Gallegos, L., \& Lerman, K. (2017). Travel analytics: Understanding how destination choice and business clusters are connected based on social media data. Transportation Research Part C: Emerging Technologies, 77, 245-256.

Kennell, S., \& Rushton, A. M. (2015, July). User-generated content (UGC) in pleasure travel decision-making. In Academy of marketing conference: The magic in marketing (pp. 77-92). Helensburgh: Academy of Marketing.

Kenton, W. (2019, April 16). Analysis of Variance (ANOVA). https://www.investopedia.com/t

Kim, H. Y. (2014). Analysis of variance (ANOVA) comparing means of more than two groups. Restorative Dentistry \& Endodontics, 39(1), 74-77.

Li, S. C., Robinson, P., \& Oriade, A. (2017). Destination marketing: The use of technology since the millennium. Journal of Destination Marketing \& Management, 6(2), 95-102.

64 Consortia Academia Publishing (A Partner of Tourism Educators and Movers of the Philippines) 
Influence of travel vlog: Inputs for destination marketing model

Liang, A. (2020). Exploring the formation and representation of destination images in travel vlogs on social media. Tour related decisions. International Journal of Education and Research, 5(5), 203-208.

Lodha, R., \& Philip, L. (2019). Impact of travel blogs and vlogs on the decision making among the students of Bangalore. International Journal of Scientific Research and Review, 7(3), 2279-2543.

Luo, Q., \& Zhong, D. (2015). Using social network analysis to explain communication characteristics of travel-related electronic word-of-mouth on social networking sites. Tourism Management, 46, 274-282.

Maity D., \& Racat, M. (2018). The role of audience comments in YouTube Vlogs: An abstract. In N. Krey \& P. Rossi (Eds.), Boundary blurred: A seamless customer experience in virtual and real spaces. Springer. https://doi.org/10.1007/978-3-319-99181-8_178

Majeed, S., Zhou, Z., Lu, C., \& Ramkissoon, H. (2020, March 12). Online tourism information and tourist behavior: A structural equation modeling analysis based on a self-administered survey. https://doi.org/10.3389/fpsyg.2020.00599

Marasco, A., Buonincontri, P., van Niekerk, M., Orlowski, M., \& Okumus, F. (2018). Exploring the role of next-generation virtual technologies in destination marketing. Journal of Destination Marketing \& Management, 9, 138-148. https://doi.org/10.1016/j.jdmm.2017.12.002

McBride, R. (2016). Designing for the digital native: Generation Z. https://lodgingmagazine.com/

Munnukka, J., Maity, D., Reinikainen, H., \& Luoma-aho, V. (2019). Thanks for watching. The effectiveness of YouTube vlogendorsements. Computers in Human Behavior, 93, 226-234. https://doi.org/10.1016/j.chb.2018.12.014

$\mathrm{Ng}$, B., \& Ho, G. (2018). An integrated cognitive perspective of travel motivation and repeated travel behaviour. Ann Cogn Sci, 1(2), 60-68. https://doi.org/10.36959/447/341

Nhon, H., \& Thu, N. (2014, July 11). Factors affecting travel-decision making: A study of the credibility of online travel-related information in Vietnam.

Ontiveros, J. (2016, Nov 10). The impact of travel blogs in destination experience: An e-ethnographic investigation. http://arno.uvt.nl/show.cgi?fid=135452

Pamuji, D. D., Yulianto, E., \& Kusumawati, A. (2020). Travel Vlog Dalam Menciptakan Dan Mempromosikan Destination Image. Profit: Jurnal Administrasi Bisnis, 53-60.

Peralta, R. L. (2019). How vlogging promotes a destination image: A narrative analysis of popular travel vlogs about the Philippines. Place Branding and Public Diplomacy, 15(4), 244-256. https://doi.org/10.1057/s41254-019-00134-6

Pestana, M. H., Parreira, A., \& Moutinho, L. (2020). Motivations, emotions and satisfaction: The keys to a tourism destination choice. Journal of Destination Marketing \& Management, 16, 100332. https://doi.org/10.1016/j.jdmm.2018.12.006

Phau, I., Quintal, V., \& Shanka, T. (2014). Examining a consumption values theory approach of young tourists toward destination choice intentions. International Journal of Culture, Tourism and Hospitality Research.

Ricci, A. (2019, February 05). Top Instagram travel influencers that can help grow your brand. https://www.wetravel.com/stories/top-instagram-travel-influencers/

Study of the Credibility of Online Travel-Related Information in Vietnam. VNU Journal of Science: Economics and Business, 30(2), 65-74.

Tanford, S., \& Montgomery, R. (2015). The effects of social influence and cognitive dissonance on travel purchase decisions. Journal of Travel Research, 54(5), 596-610.

Thurm, M. C. (2014). The impact of travel blogging on the tourist experience: An e-ethnographic investigation. Tilburg University, 1-141.

Travel influencers: A new concept for the tourism sector. (2019, October 17). https://influencity.com/blog/en/travel-influencers-a-new-concept-for-the-tourism-sector-2/

Trinh, V. D., \& Nguyen, L. (2019, June). How to change perceived destination image through Vlogging on Youtube. In the Proceedings of the 1st International Conference on Management Science 'Digital Disruption Era: Challenges and Opportunities for Business Management. 
Abad, P. E. S., \& Borbon, N. M. D.

View of Travel blogging: An auto-ethnographic study of how online interactions influence a journey: First Monday. (n.d.). https://firstmonday.org/ojs/index.php/fm/article/view/4887/4098

Wei, L. (2016). Decision-making behaviours toward online shopping. International Journal of Marketing Studies, 8(3), 111. https://doi.org/10.5539/ijms.v8n3p111

Werenowska, A., \& Rzepka, M. (2020). The role of social media in generation Y travel decision-making process (case study in Poland). Information, 11(8), 396. https://doi.org/10.3390/info11080396

Wojciechowicz, J. K. (2020). YouTube airline review vloggers' impact on their followers' purchase intent (Doctoral dissertation). Dublin, National College of Ireland.

Yiamjanya, S., \& Wongleedee, K. (2014). International tourists' travel motivation by push-pull factors and the decision making for selecting Thailand as destination choice. International Journal of Social, Behavioral, Educational, Economic, Business and Industrial Engineering, 8(5), 1348-1353.

Zahid, Z., \& Ahmed, M. (2017). Role of image value and functional value in developing the purchase intentions and WOM Marketing. European Journal of Business and Management, 9(7).

Zhang, Y., \& Chikwaya, T. (2018). Commerce \& Friendship: A qualitative study of new value streams created by beauty vloggers through relationship building on social media.

Zhumadilova, A. (2016). The impact of TV shows and video blogs on tourists' destination choice. Tourism Today, 16, 148-166. 